\title{
Dynamics of Upper Urinary Tract during Pacemaker Blockade Induced by Pentobarbital
}

\author{
Osamu Yamaguchi and Seigi Tsuchida \\ Department of Urology, Akita University School of Medicine, \\ Akita 010
}

\begin{abstract}
Yamagochi, O. and Tsuchida, S. Dynamics of Upper Urinary Tract during Pacemaker Blockade Induced by Pentobarbital. Tohoku J. exp. Med,, 1979, 127 (1), 9-15 - The transport efficiency of the dog's pelviureteral system was examined during pacemaker blockade induced by pentobarbital. For an analog representation of transport efficiency, changes in balance level between the input and the output were registered and recorded on a polygraph together with perfusion rate, renal pelvic pressure, ureteral electromyogram and bolus volume. Pentobarbital dramatically blocked the pacemaker activity of the renal pelvis, and the ureter simultaneously became aperistaltic. During the period of pacemaker rest, the balance level was maintained at a high level in all dogs studied, indicating that a part of the perfusion fluid was accumulated in the pelviureteral system. Furthermore, the accumulated fluid overflowed through the aperistaltic ureter as a free flow. These results are discussed in relation to the transport efficiency of normal peristaltic transport. — balance level; pelviureteral system; ureteral peristalsis
\end{abstract}

Under physiologic conditions the urine in the renal pelvis is subsequently transported by ureteral peristalsis to the bladder. With regard to the mechanisms involved in the initiation of ureteral peristalsis, it has been established, mainly in dogs, that the renal pelvis acts as a pacemaker (Constantinou 1974; Hrynczuk and Schwartz 1975). However, the functional characteristics of the peristaltic transport, especially in the transport efficiency correlated to the formation of urine bolus, are not yet completely understood.

Recently, Constantinou and Hrynczuk (1976) showed that Pentothal (thiopental) anesthesia altered the rhythmicity of the renal pelvic pacemaker and simultaneously changed the active form of peristaltic transport to a passive manner. The present paper also demonstrates the inhibitory effect of pentobarbital on the activity of the renal pelvis and ureter, and examines the transport efficiency of the pelviureteral system during the pacemaker blockade induced by this anesthetic.

\section{Materials and Methods}

Seven mongrel dogs weighing between 15 and $20 \mathrm{~kg}$ were used. The dogs were anesthetized with an intravenous injection of sodium pentobarbital (Nembutal, 25-30 $\mathrm{mg} / \mathrm{kg}$ ), and the kidney, ureter and bladder were exposed by a transperitoneal midline incision.

Received for publication, February 10, 1978. 
A 16G-double lumen cannula was inserted through the parenchyma into the renal pelvis. One lumen was used for the perfusion, and the other was connected to a Statham P-37 transducer to record the renal pelvic pressure. The renal pelvis was infused by warm saline and the perfusion rate was recorded by a drop counter which was attached to a small drip chamber of the infusion tube. A $5 \mathrm{Fr}$. polyethylene catheter was inserted in the ureter $1 \mathrm{~cm}$ above the ureterovesical junction, and was connected to another drop counter to record the output from the ureter. The two drop counters were calibrated to the same sensitivity of $0.0148 \mathrm{ml} /$ drop.

For the measurement of ureteral peristalsis, a suction electrode (Hamilton, Co.) was placed on the surface of the midureter by the use of a micromanipulator. Finally, as shown in Fig. 1, recordings of four parameters (the perfusion rate as the input, the renal pelvic pressure, the ureteral electromyogram and the bolus volume as the output) were simultaneously made.

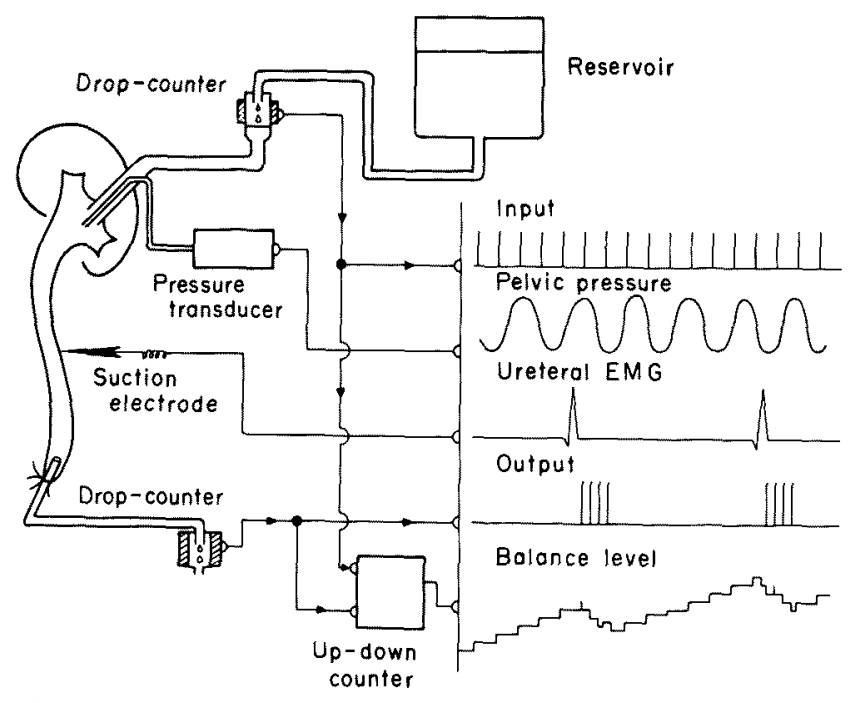

Fig. 1. Experimental design to measure the balance level between the input and the output. The perfusion rate, renal pelvic pressure, ureteral EMG and bolus volume are simultaneously recorded.

Changes in the balance level between the input and the output were registered as the graphic representation of peristaltic transport efficiency. The detailed description of this technique was previously reported (Yamaguchi and Tsuchida 1977).

To minimize the influence of spontaneous urine flow on this perfusion study, the experiments were started after the urine flow from the studied kidney was recognized to be below $0.03 \mathrm{ml} / \mathrm{min}$. The perfusion rate which ranged from 0.16 to $0.58 \mathrm{ml} / \mathrm{min} /$ ureter was maintained at a constant value in each individual dog throughout the experiment.

The normal peristaltic transport was briefly examined in 3 dogs. The remaining 4 dogs were used to evaluate the effect of pentobarbital on the transport efficiency. After recordings of four parameters were made as a control, $1 \mathrm{ml}$ of Nembutal (50 mg pentobarbital) was administered intravenously to block the activity of both pacemaker and ureter. During the period of inactivity following the additional administration of the anesthetic, the same recordings were also made. 


\section{RESUlts}

Fig. 2 illustrates normal peristaltic transport when the perfusion rate was 0.274 $\mathrm{ml} / \mathrm{min} /$ ureter. In this recording, the renal pelvic pressure showed rhythmic contraction waves which were triggered by the renal pelvic pacemaker. The interval between two pressure waves was approximately $3.0 \mathrm{sec}$ and constant throughout the recording. At this intermediate perfusion rate, some of pacemaker contractions initiated the ureteral peristalsis. Thus, the interperistaltic interval of the ureter was shown as a multiple of the basic $3.0 \mathrm{sec}$ interval of the pacemaker and varied among 4,6,7 and 8 times in this case. This definite relation between the renal pelvic pressure and the ureteral peristalsis was consistently found in all dogs over the control period.

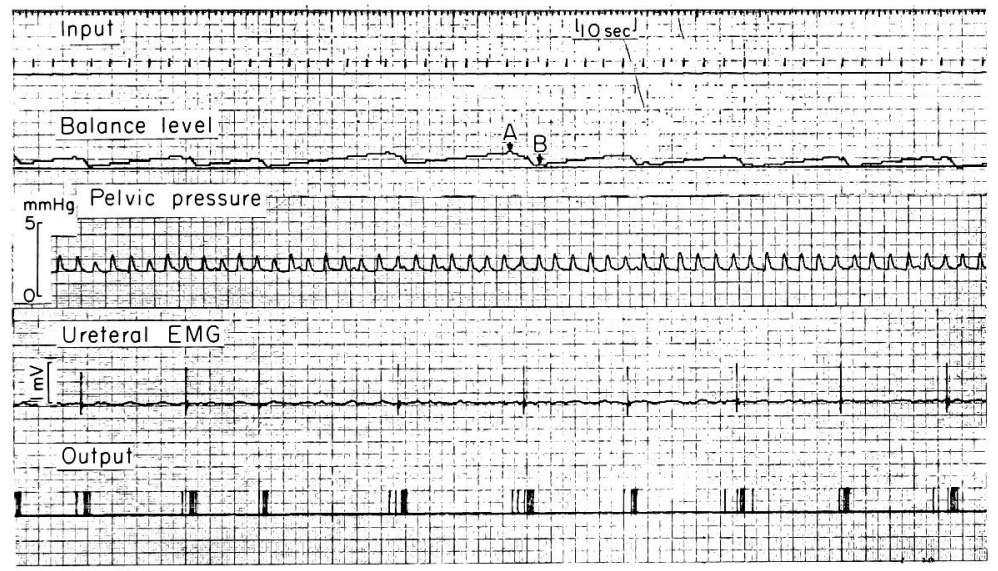

Fig. 2. Normal peristaltic transport. Mean perfusion rate was $0.274 \mathrm{ml} / \mathrm{min} /$ ureter. Note that the postperistaltic level $(B)$ is approximately constant throughout the recording.

Changes in the balance level associated with the peristaltic transport are also demonstrated in Fig. 2. During the resting period of ureteral peristalsis, the balance level was increased in a step-wise manner at the same rate with the perfusion until it reached the preperistaltic level ( $A$ in Fig. 2). When the bolus was excreted by the subsequent peristalsis, the balance level rapidly decreased to the postperistaltic level ( $B$ in Fig. 2). It is evident from Fig. 2 that the postperistaltic level was maintained at an approximately constant level throughout the recording. This constancy of the postperistaltic level was consistently observed in normal peristaltic transport in which the ureteral peristalsis was controlled by the pacemaker.

The effect of increasing the extent of pentobarbital anesthesia on the peristaltic transport is demonstrated in Figs. 3 and 4 . As all 4 dogs used in this experiment showed similar results, the recordings of 2 dogs will be shown and 
described in detail. Fig. 3A is the control recording obtained from dog No. 5. As already mentioned, the balance level showed typical changes associated with the peristaltic transport.
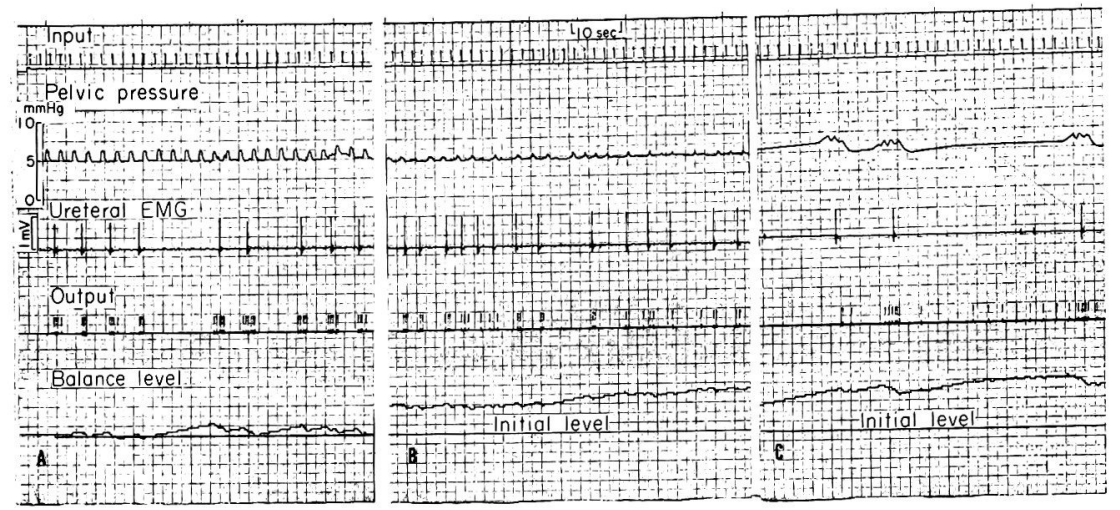

Fig. 3. The effect of pentobarbital on the peristaltic transport. Mean perfusion rate was $0.414 \mathrm{ml} / \mathrm{min} /$ ureter. A, control; $\mathrm{B}$ and $\mathrm{C}$, the segment recording $4 \mathrm{~min}$ and $10 \mathrm{~min}$ after intravenous administration of $1 \mathrm{ml}$ Nembutal, respectively.

Generally, the constant rhythm of the renal pelvic pressure was altered within $30 \mathrm{sec}$ from the start of anesthetic injection. As shown in Fig. 3B which represents the segment recording $4 \mathrm{~min}$ after intravenous administration of $1 \mathrm{ml}$ Nembutal, the rhythmicity of renal pelvic pressure was slightly disturbed; however, ureteral peristalsis was still initiated by the weak contractions of the renal pelvis. Furthermore, the bolus volume excreted by each peristaltic contraction was slightly decreased. Thus, as compared with the control recording (Fig. 3A), the balance level was elevated during the period of pacemaker arrhythmia.

The effect of increasing pentobarbital anesthesia on the peristaltic transport reached its maximum approximately 10 to $20 \mathrm{~min}$ after intravenous administration. Thus, as shown in Fig. 3C, the pacemaker activity was further blocked and ureteral peristalsis was elicited much less frequently. The balance level was also maintained at a higher level than the control and changed approximately parallel with the renal pelvic pressure, indicating that most of the perfusion fluid was accumulated in the pelviureteral system. In addition, the accumulated fluid passively flowed out through the ureter as a non-peristaltic flow.

Similar results from a different $\operatorname{dog}($ No. 6) are illustrated in Fig. $4 \mathrm{~A}$ and B. In this case, the pacemaker activity was periodically interrupted. In Fig. 4B, within the first interval of pacemaker rest, ureteral peristalsis was concomitantly blocked and non-peristaltic flow took place; however, the balance level remained high and never returned to the control postperistaltic level shown in Fig. 4A. When the rhythmicity of the renal pelvic pressure returned to that of the pacemaker as shown at the middle part of Fig. 4B, the balance level was rapidly 
lowered to the control postperistaltic level by each peristaltic contraction. Within the second interval of pacemaker rest following this incidence, the balance level was again increased. With an increase in the amount of perfusion fluid in the pelviureteral system, a free flow was also observed. However, this free flow never lowered the balance level to that of the control.
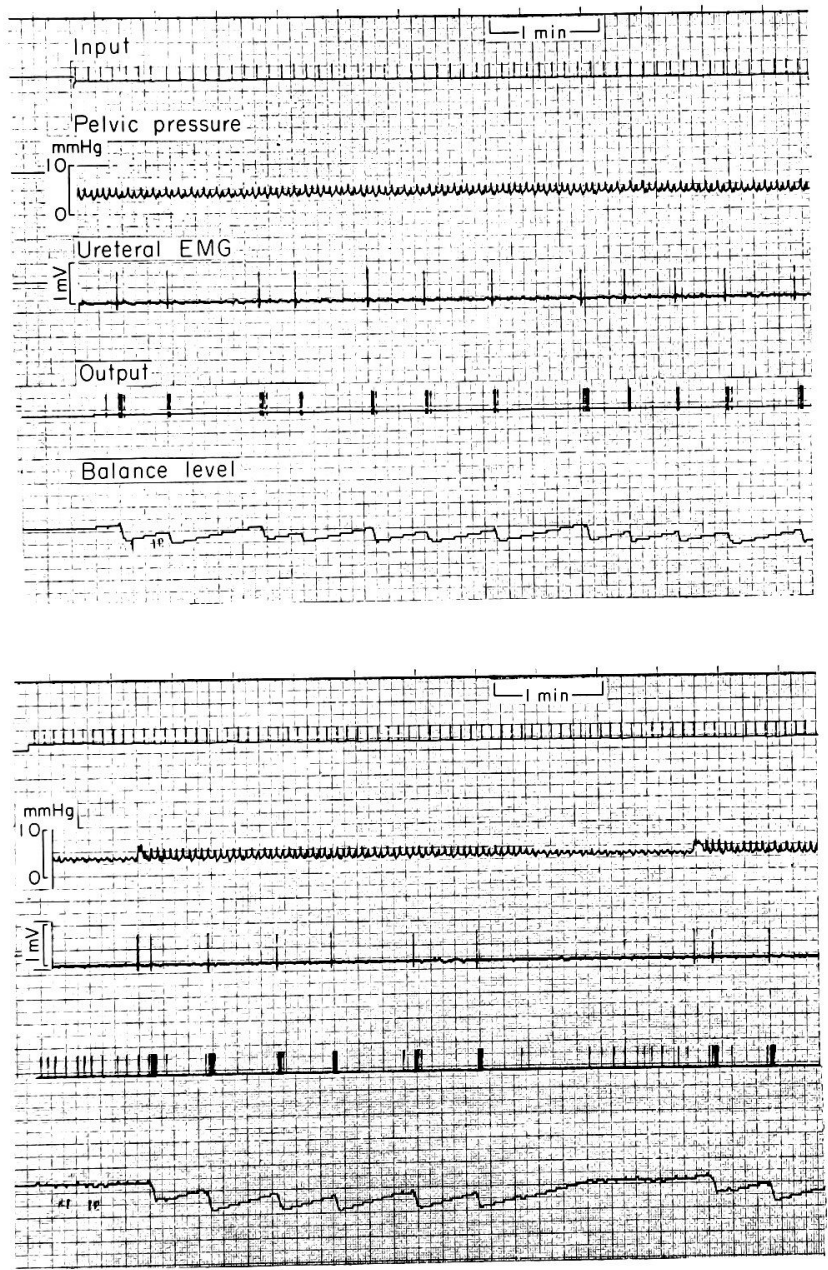

Fig. 4. A case showing periodical blockade of the pacemaker activity. A, control; B, the segment recording $15 \mathrm{~min}$ after administration of $1 \mathrm{ml}$ Nembutal. Mean perfusion rate was $0.16 \mathrm{ml} / \mathrm{min} /$ ureter.

\section{Discussion}

It is well known that the ureteral peristalsis transports urine as discrete urine bolus to the bladder. In this experiment, the dogs were anesthetized with pentobarbital; however, the recording before additional administration of the 
same anesthetic showed that the ureteral peristalsis was always accompanied with an ensemble of drops as the bolus. Such a form of transport is also observed by clinical x-ray examinations (intravenous pyelography, cineradiography) in unanesthetized man. Thus, the characteristic feature of normal peristaltic transport appears to be still maintained in the control recording as shown in Fig. 2.

In normal peristaltic transport under the control of the pacemaker, changes in balance level were strictly associated with ureteral peristalsis, and the postperistaltic level was maintained at an approximately constant level (Fig. 2). Thus, it can be said that each peristaltic contraction completely excretes the volume of perfusion fluid which has been accumulated in the pelviureteral system during the preceding interperistaltic interval. This result appears to be a criterion for examining the transport efficiency during the period of pacemaker blockade.

The effect of thiopental anesthesia on the pacemaker activity was previously described by Constantinou and Hrynczuk (1976). The present study showed that pentobarbital also blocked the rhythmicity of the renal pelvic pacemaker, and this resulted in the cessation of ureteral peristalsis. During the period of pacemaker blockade, it was demonstrated that the balance level tended to increase in all dogs studied.

At a lower extent of pacemaker blockade as shown in Fig. 3B, it was observed that irregular, weak contractions of the renal pelvis could not form a sufficient bolus with a large volume. Thus, the perfusion fluid was gradually accumulated in the pelviureteral system, and this resulted in the elevation of the balance level.

When the effect of pentobarbital reached the maximum extent, the long interval of pacemaker rest was well recognized (Figs. 3C and $4 \mathrm{~B}$ ). Within this interval, the ureter became aperistaltic as the peristaltic contraction could not be initiated in this state. Thus, the perfusion fluid was accumulated in the pelviureteral system and the balance level was gradually increased. Finally, the accumulated fluid overflowed through the aperistaltic ureter, and the form of transport became passive.

This free flow interrupted further increase in balance level, but it was consistently observed that the balance level still remained high within the interval of pacemaker rest (Figs. $3 \mathrm{C}$ and $4 \mathrm{~B}$ ). Therefore, compared with peristaltic transport, the free flow of this passive transport is less effective in removing the fluid from the system.

In addition, it was observed that the free flow never markedly occurred until the balance level became high enough. Thus, the perfusion fluid tended to be accumulated in the system before it passively flowed out through the ureter. It is assumed from this result that pentobarbital influences not only the pacemaker activity but also the inherent tension of the upper urinary tract. Thus, pentobarbital appears to decrease the tonus of the renal pelvis and ureter, and this effect may account for the accumulation of perfusion fluid during such instances. 


\section{References}

1) Constantinou, C.E. (1974) Renal pelvic pacemaker control of ureteral peristaltic rate. Amer. J. Physiol., 226, 1413-1419.

2) Constantinou, C.E. \& Hrynezuk, J.R. (1976) Renal pelvic pacemaker arrhythmias induced by pentothal anesthesia. Urol. int., 31, 489-500.

3) Hrynczuk, J.R. \& Schwartz, T.W. (1975) Rhythmic contractions in the renal pelvis correlated to ureteral peristalsis. Invest. Urol., 13, 25-30.

4) Yamaguchi, O. \& Tsuchida, S. (1977) A method to register a dynamic balance of the upper urinary tract. Tohoku J. exp. Med., 123, 295-296. 